Article

\title{
Permeable Water-Resistant Heat Insulation Panel Based on Recycled Materials and Its Physical and Mechanical Properties
}

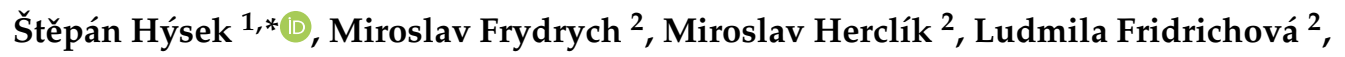 \\ Petr Louda ${ }^{1}(\mathbb{D})$, Roman Knížek ${ }^{2}$, Su Le Van ${ }^{1}$ and Hiep Le Chi ${ }^{1}$ (D) \\ 1 Department of Material Science, Faculty of Mechanical Engineering, Technical University of Liberec, \\ Studentska 2, 46117 Liberec, Czech Republic \\ 2 Department of Textile Evaluation, Faculty of Textile Engineering, Technical University of Liberec, \\ Studentska 2, 46117 Liberec, Czech Republic \\ * Correspondence: hysekstepan@seznam.cz; Tel.: +420-607-501-858
}

Academic Editors: Pietro Russo and Fabrizio Sarasini

Received: 7 August 2019; Accepted: 10 September 2019; Published: 11 September 2019

\begin{abstract}
This paper deals with the development and characteristics of the properties of a permeable water-resistant heat insulation panel based on recycled materials. The insulation panel consists of a thermal insulation core of recycled soft polyurethane foam and winter wheat husk, a layer of geopolymer that gives the entire sandwich composite strength and fire resistance, and a nanofibrous membrane that permits water vapor permeability, but not water in liquid form. The observed properties are the thermal conductivity coefficient, volumetric heat capacity, fire resistance, resistance to long-term exposure of a water column, and the tensile strength perpendicular to the plane of the board. The results showed that while the addition of husk to the thermal insulation core does not significantly impair its thermal insulation properties, the tensile strength perpendicular to the plane of these boards was impaired by the addition of husk. The geopolymer layer increased the fire resistance of the panel for up to $13 \mathrm{~min}$, and the implementation of the nanofibrous membrane resulted in a water flow of $154 \mathrm{~cm}^{2}$ in the amount of $486 \mathrm{~g}$ of water per $24 \mathrm{~h}$ at a water column height of $0.8 \mathrm{~m}$.
\end{abstract}

Keywords: heat insulation; sandwich panel; polyurethane foam; geopolymer; nanofiber membrane

\section{Introduction}

One of the most important challenges for the construction industry is to reduce the energy demands of buildings throughout their entire life cycle. During the use of a building, its thermal demands are undoubtedly influenced by its insulation. Commonly used thermal insulation materials for building insulation are produced from petrochemical products or from natural sources, but their production is highly energy intensive (glass, rock, wool) [1]. From this perspective, the use of recycled and plant materials is very promising for the production of thermal insulation. In the case of plant materials, rice husks [2], sunflower stalks [3], wheat straw [4], wheat husks [5] flax fibers [6], hemp fibers [7], larch bark [8], and many others can be considered for thermal insulation production. Recycling synthetic materials or using agricultural or industrial residues can be an effective way to reduce virgin materials consumption [9]. Products from recycled plastics such as polyethylene terephthalate [10] and recycled textile fibers [11] provide very good thermal insulation properties.

However, a significant disadvantage of plant materials consisting mainly of cellulose, hemicelluloses, lignin, and pectins is their flammability [12]. In terms of building materials, their resistance to burning by geopolymer applications $[13,14]$ can be improved significantly. Geopolymers are materials usually synthesized using an aluminosilicate raw material and an activating solution 
mainly composed of alkalis of sodium or potassium and water glass $[15,16]$. Due to the properties of geopolymers in the form of high strength, resistance to chemicals and, in particular, thermal stability and fire resistance, applications of these geopolymers in the form of protective coatings or coatings on structures [17-21] have been studied in recent years. In the past, the fire resistance of particleboards based on winter rapeseed stalks [13] has been successfully increased by the geopolymer layer. Even better geopolymer properties can be achieved, for example, via the implementation of carbon fibers, which result in better mechanical properties of the entire composite [22].

An important property of cellulose-based plant fibers is hygroscopicity. This property may be an advantage in some applications and a disadvantage in other applications. However, in terms of thermal insulation of structures, high humidity in the insulation is undesirable, as water reduces the thermal insulation properties of the material [23]. On the other hand, we require, from natural fiber, thermal insulation interior vapor permeability through the building envelope to the exterior [24,25]. Preventing the permeability of liquid water from the exterior into the building envelope and, at the same time ensuring the transport of water vapor from the interior through the building envelope to the exterior, is ensured by a suitably-selected wall structure [26]. One of the elements that can be used in the wall structure for this purpose can be a nanofibrous membrane, which provides water vapor permeability, but prevents the permeability of water in the liquid state [27]. In addition, a suitably-designed nanofibrous membrane can withstand a very high water column, which can affect the building, for example during floods [27].

This paper deals with the use of post-harvest residues of winter wheat and recycled polyurethane foam in combination with geopolymer foam and a nanofibrous membrane for the production of composite materials with properties for the given purpose of use. The aim of this work is to determine the influence of winter wheat husk and the implementation of a nanofibrous membrane and a geopolymer layer into the sandwich panel structure on its mechanical and physical properties. This paper contributes to finding material utilization of wheat husks, which provides storage of $\mathrm{CO}_{2}$ in comparison with energetic utilization of this raw material. Moreover, addition of husks into the heat insulation panel may bring additional benefits during manufacturing of these panels. Since wheat husks contain $12.7 \%$ moisture [5], no steam injection would be necessary for hardening of polyurethane adhesive.

\section{Materials and Methods}

\subsection{Heat Insulation Board Manufacturing}

The insulation boards were made of crushed flexible polyurethane (PUR) foam, winter wheat husk, and PU4349/3 one component moisture curing binder (Leeson Polyurethanes Ltd., Warwick, UK). The crushed flexible PUR foam was supplied by the Molitan company (Molitan a. s., Breclav, Czech republic) as recyclate from manufacturing rests. The apparent density of the used PUR foam was $24 \mathrm{~kg} / \mathrm{m}^{3}$ and the bulk density was $11.3 \mathrm{~kg} / \mathrm{m}^{3}$. The PUR particle fraction analysis is shown in the results. Winter wheat husks were mixed into the boards at $0 \%$ and $25 \%$ to the weight of the PUR recycled material. The analysis of the husk fraction is presented in the results. The adhesive was applied to the particles by spraying in a laboratory adhesive applicator, and the proportion of adhesive on the dry matter was $15 \%$. The carpet was manually layered and compressed between the steel screens, and curing was carried out in a heat chamber at an air temperature of $120^{\circ} \mathrm{C}$ for $15 \mathrm{~min}$. The boards were then air conditioned at $20^{\circ} \mathrm{C}$ and $65 \%$ relative humidity (RH) for 3 days. Figure 1 shows the surface view of the thermal insulation boards. 

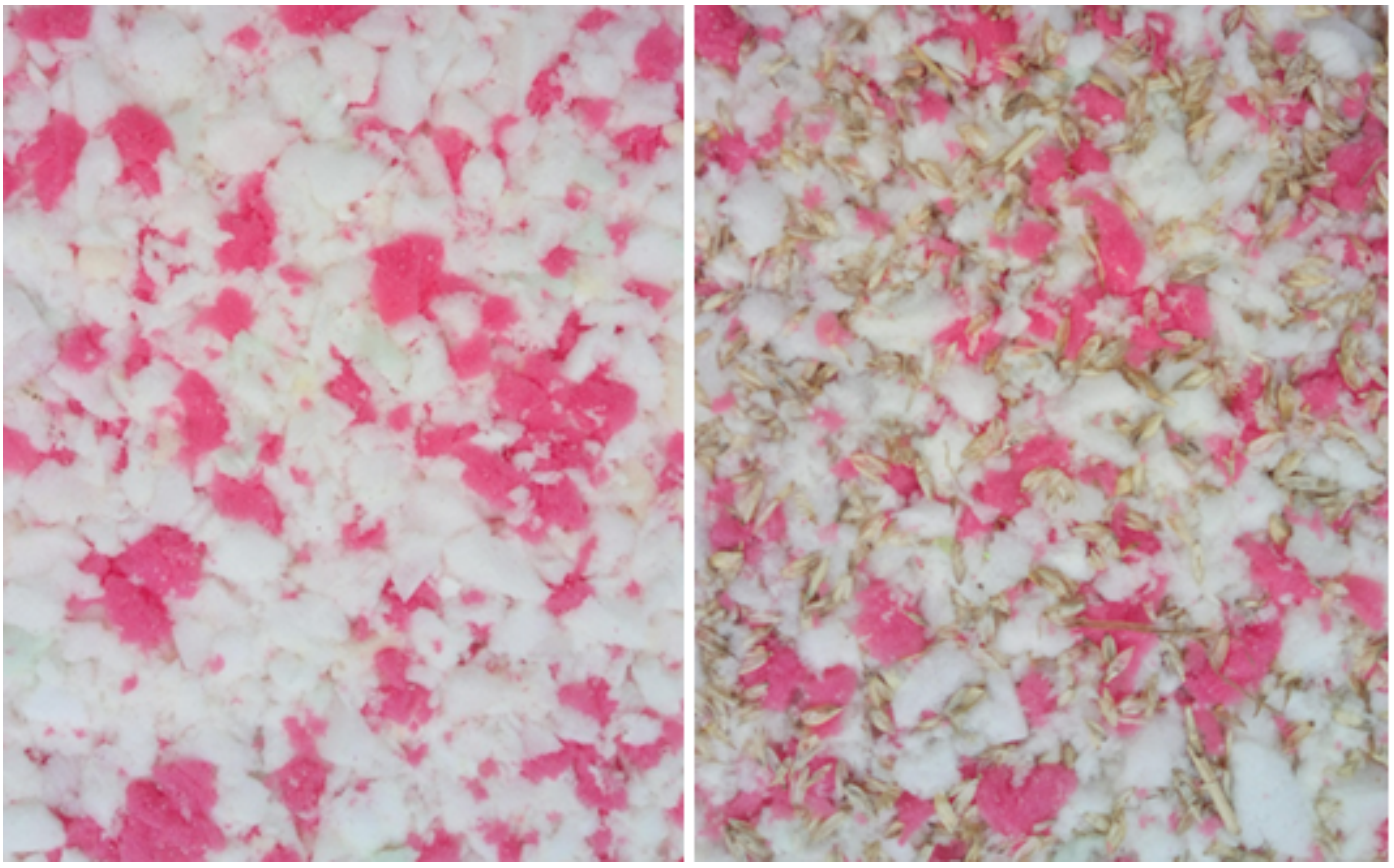

Figure 1. Surface view of the thermal insulation layer, board without husks on the left, board with addition of husks on the right.

\subsection{Geopolymer and Nanofiber Membrane Application}

A geopolymer layer of $1 \mathrm{~cm}$ thickness and a density of $880 \mathrm{~kg} / \mathrm{m}^{3}$ was applied to one side of the insulation board to increase its fire resistance. The composition of the geopolymer is shown in Table 1. A more detailed identification of its composition is given in previously published research [13]. A nanofibrous membrane was manually deposited on the surface of the freshly-applied and uncured geopolymer. The nanofibrous membrane was implemented into the composite due to the above-described reason in order to prevent the permeability of water molecules in a liquid state, but allowing for the permeability of water vapor. In order to protect the nanofiber membrane from damage, it was laminated between two non-woven fabrics made from polyester with a basic weight of $55.6 \mathrm{~g} / \mathrm{m}^{2}$. The nanofiber membrane was made of polyurethane via electrospinning using Nanospider technology (Elmarco s.r.o., Liberec, Czech Republic). The solution was spun in an electric field with a voltage of $80.7 \mathrm{kV}$, the distance of the condenser was $190 \mathrm{~mm}$, the velocity of the supporting base fabric was $0.1 \mathrm{~m} / \mathrm{min}$, the relative humidity in the spinning chamber was $21 \%$, and the surface weight of the produced nanofibrous layer was $6 \mathrm{~g} / \mathrm{m}^{2}$.

Table 1. Geopolymer composition.

\begin{tabular}{cc}
\hline Component & Percentage of Individual Components \\
\hline Cement Baucis Lk & $43.2 \%$ \\
\hline Activator Baucis Lk & $38.9 \%$ \\
\hline KEMA MIKROSILIKA & $4.3 \%$ \\
\hline Mineral wool ISOVER & $13.0 \%$ \\
\hline Aluminum powder & $0.6 \%$ \\
\hline
\end{tabular}

Table 2 shows the variants of the sandwich composites being developed. Two variants of the percentage husk representation were chosen and composites with and without a membrane were made. The geopolymer layer was always constant. Figure 2 shows a cut of the sandwich panel. 
Table 2. Variants of the manufactured sandwich-structured panel.

\begin{tabular}{ccccc}
\hline & \multicolumn{3}{c}{ Permeable Water-Resistant Heat Insulation Panel } \\
\hline Recycled PUR:wheat husk ratio & \multicolumn{2}{c}{$1: 0$} & $3: 1$ \\
\hline Nanofiber membrane & 0 & 1 & 0 & 1 \\
\hline & Note: polyurethane (PUR).
\end{tabular}

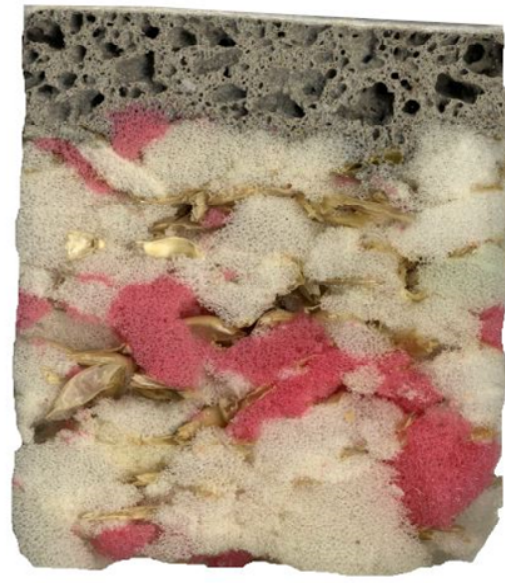

Figure 2. View of sandwich panel cut.

\subsection{Physical and Mechanical Properties Estimation}

All of the tests were carried out after air conditioning of the material under conditions of $20^{\circ} \mathrm{C}$ and $65 \%$ relative humidity. The distribution of husks and crushed PUR foam fraction was determined via a screen analysis and the results were then graphically expressed. The density of the material was determined according to standard EN 323 [28] and internal bonding (tensile strength perpendicular to the plane of the board) according to EN 319 [29]. The methodology of these experiments is described in more detail in [13]. The thermal insulation properties of boards were measured using the Isomet 2104 device (Applied Precision, Ltd., Bratislava, Slovakia) according to the method described previously in [30], using a probe with a measuring range of 0.015 to $2 \mathrm{~W} /(\mathrm{m} \cdot \mathrm{K})$. The thermal conductivity coefficient of the entire sandwich panel was determined by a calculation, because the thermal insulation properties of the sandwich materials cannot be measured by the used method. The calculation was carried out according to the thermal resistances of the individual layers (Equation (1)) and; therefore, the total thermal conductivity coefficient of the developed sandwich panels is a theoretical value that is based on the thermal resistance values of the individual layers and does not include thermal resistance during heat transfer.

$$
\lambda_{\text {tot }}=\frac{\mathrm{d}_{\text {tot }}}{\sum \mathrm{R}_{\mathrm{i}}}=\frac{\mathrm{d}_{\mathrm{tot}}}{\sum \frac{\mathrm{d}_{\mathrm{i}}}{\lambda_{\mathrm{i}}}}
$$

where $\lambda_{\text {tot }}$. is the total thermal conductivity coefficient of the sandwich panel, $d_{\text {tot }}$ is the total thickness of the sandwich panel, $d_{i}$. is the thickness of one layer in the sandwich panel, $\lambda_{i}$ is the thermal conductivity coefficient of one layer in the sandwich panel, and $R_{i}$ is the thermal resistance of one layer in the sandwich panel.

The fire resistance of the panels was performed via a thermal loading test. This test was performed according to the methodology previously published in [13], and comes from slightly modified standard EN 1363-2 [31]. A custom-designed furnace that allows for testing samples with dimensions of $300 \mathrm{~mm} \times 300 \mathrm{~mm}$ was employed in order to characterize the behavior of the developed panels in different types of fire. Chosen external fire curves are presented in the results. Two temperature sensors were used, the first located in the burner chamber and the second on the outside of the flame. 
The course of temperatures was monitored over time. The flame intensity was controlled by the flow of gas and the flame was directed parallel to the plane of the tested sample.

The water permeability of sandwich composites was measured on our developed prototype. Unlike similar devices used to measure, for example, water column resistance, the used prototype measures the actual amount of liquid that the test sample releases over time at a defined hydrostatic pressure [27]. Samples with a circular cross section with a diameter of $17 \mathrm{~cm}$ were mounted in a test capsule using a seal and, subsequently, the surface of the sample of $154 \mathrm{~cm}^{2}$ was exposed to a water column $80 \mathrm{~cm}$ in height, corresponding to a pressure of $7.8 \mathrm{kPa}$. The water that passed through the composite was measured for $24 \mathrm{~h}$. Throughout the experiment, the constant height of the water column to which the composite was exposed was maintained.

\subsection{Statistical Analysis}

Data was statistically processed using Statistica12 software (Tulsa, OK, USA). Descriptive statistics and graphical representations were used to describe the data. The influence of the observed factors on the variables was shown graphically: Thermal conductivity coefficient, thermal capacity, tensile strength perpendicular to the level of the board. The vertical columns correspond to $95 \%$ confidence intervals. Subsequently, a Tukey posthoc test was performed to determine if any of the differences between sample means were statistically significant. A significance level of $\alpha=0.05$ was used for all analyses. The temperature course during the thermal loading test was depicted using point chart as a function of time.

\section{Results and Discussion}

Figures 3 and 4 show the distribution of the PUR foam crushed fraction and the winter wheat husk. While the predominant part of the crushed PUR foam particles is in the range of 5 to $15 \mathrm{~mm}$, the predominant part of the husk can be characterized by dimensions of 1.5 to $3 \mathrm{~mm}$. The particle size has a major influence on the mechanical properties of the boards [32]; however, in the case of the sandwich panels, where one layer is significantly stronger than the other, the geopolymer layer takes over all the flexural strength [33]. In this research, the particle size affected tensile strength perpendicular to the level of the board.

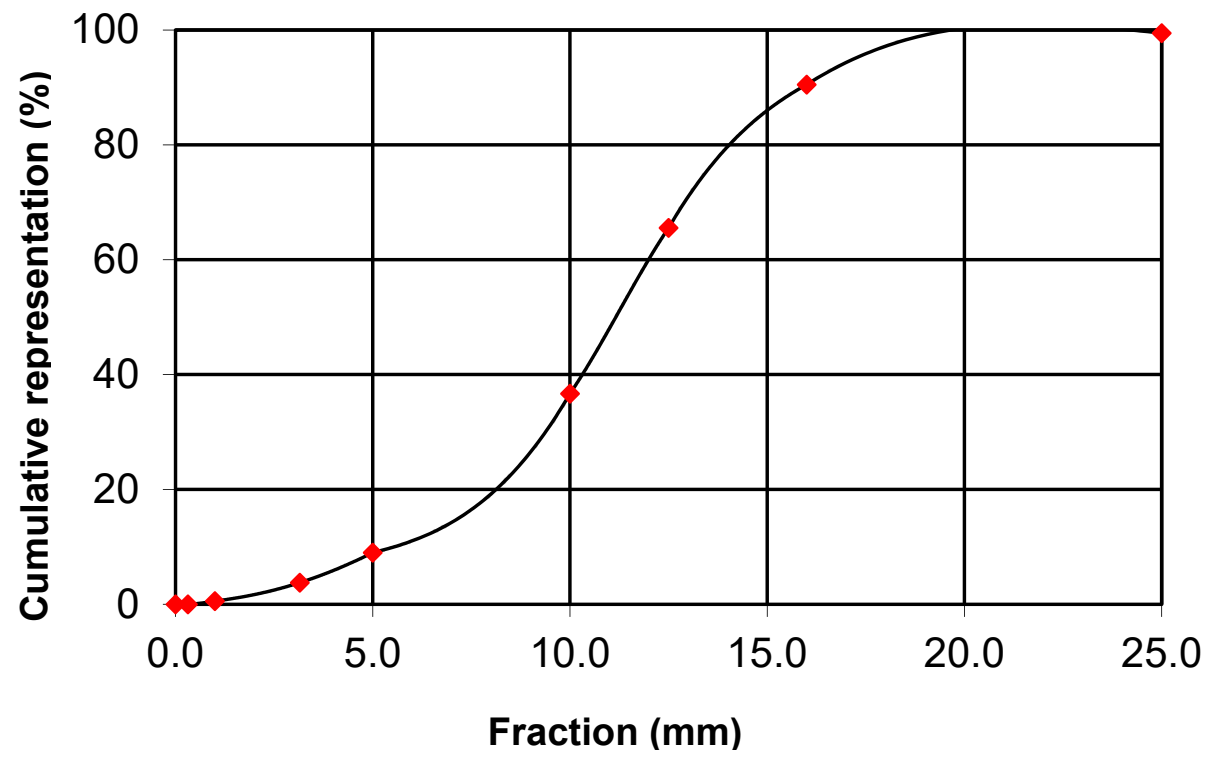

Figure 3. Fraction of crushed PUR foam. 


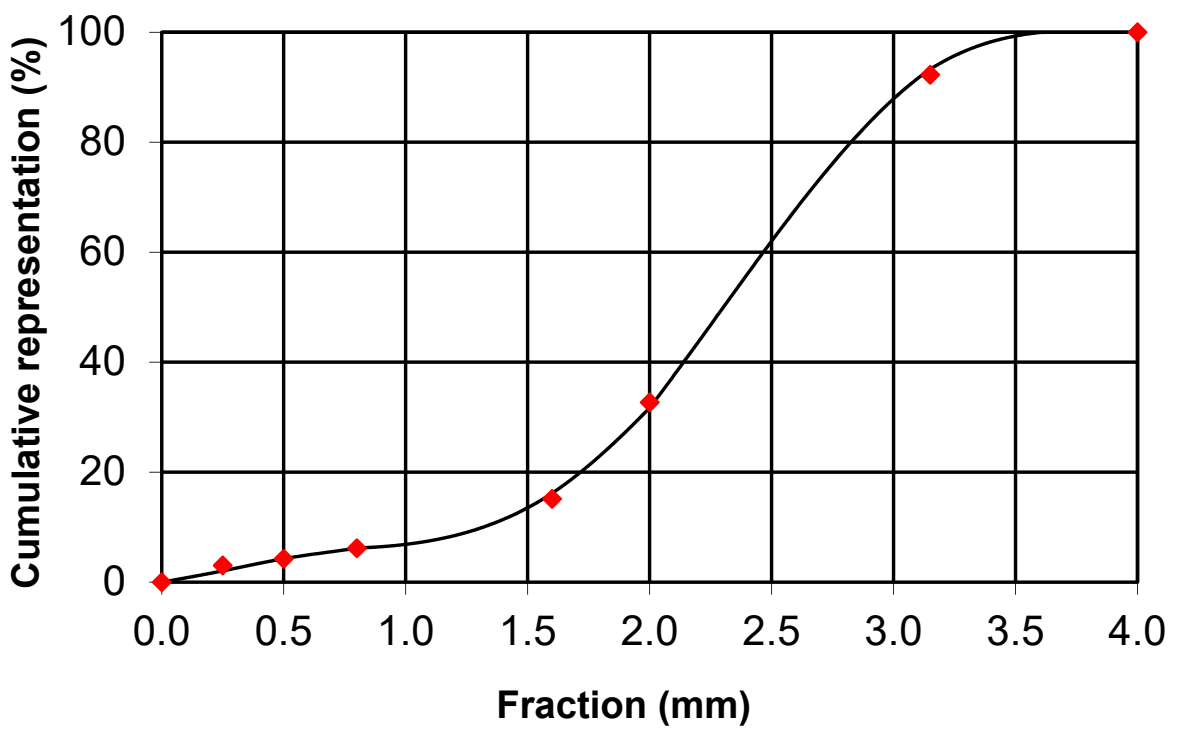

Figure 4. Fraction of winter wheat husk.

Figure 5 shows the effect of the weight ratio of husk in the insulation board on the thermal conductivity coefficient. The picture shows that in both cases the measured thermal insulation cores achieved very good thermal conductivity values in the range from 0.0427 to $0.0452 \mathrm{~W} /(\mathrm{m} \cdot \mathrm{K})$. The addition of the husk to the crushed PUR foam resulted in a slight deterioration of $0.0025 \mathrm{~W} /(\mathrm{m} \cdot \mathrm{K})$ (a statistically significant difference); nevertheless, these are still very good values compared to other alternative raw materials. The achieved thermal conductivity values are slightly lower than in the case of thermal insulation boards made from reeds [1], bagasse [34], or cotton stalks [35]. However, it should be noted that, in the above competing products, the manufactured boards had a higher density. For example, $30 \mathrm{~kg} / \mathrm{m}^{3}$ recycled polyethylene terephthalate boards achieved a thermal conductivity coefficient of $0.0355 \mathrm{~W} /(\mathrm{m} \cdot \mathrm{K})$ [10].

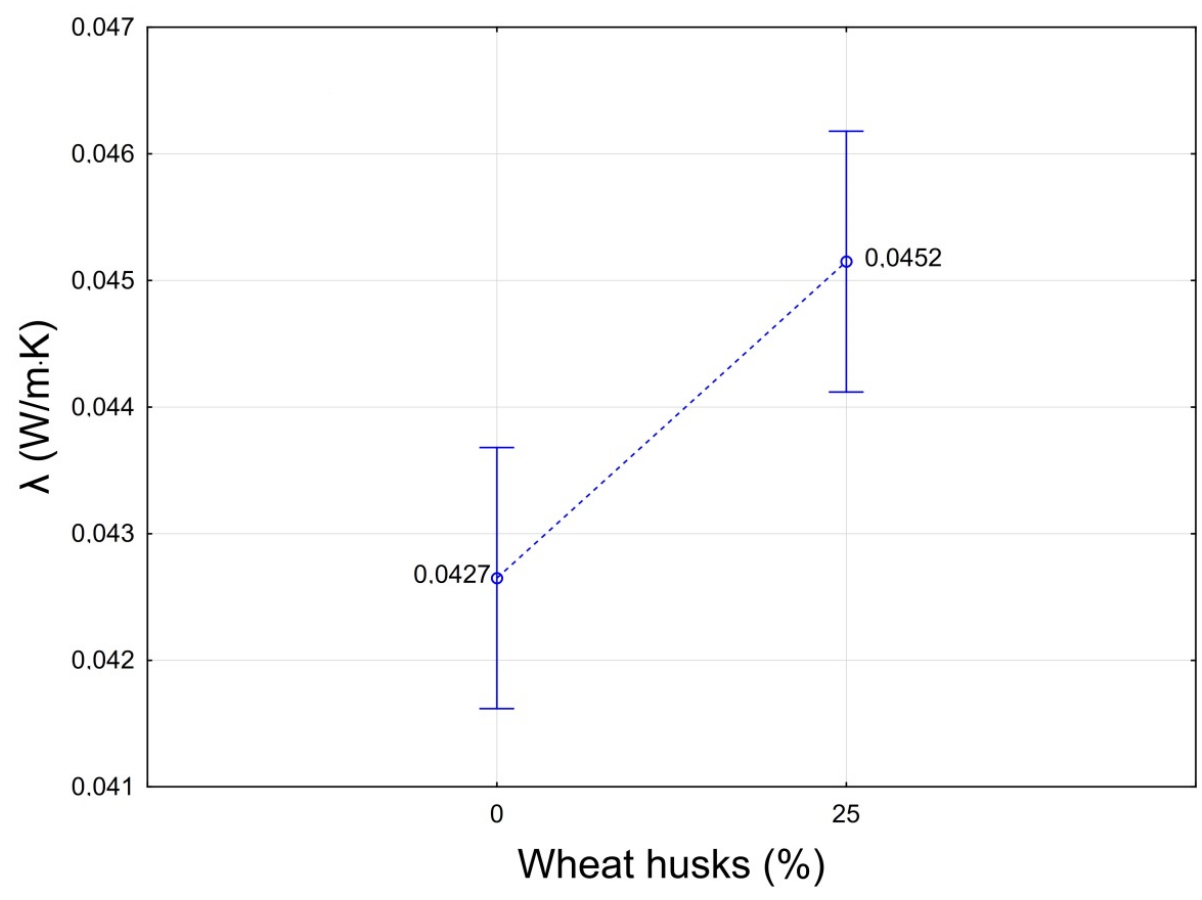

Figure 5. Influence of the proportion of the husk in the insulation board on the thermal conductivity coefficient. 
Figure 6 shows the effect of the weight proportion of husk in the insulation board on the volumetric heat capacity. The difference between the individual variants is statistically significant at a level of 0.05 . As with the thermal conductivity coefficient, the addition of husk increased this characteristic. However, in this case, this is an improvement in the characteristic that can compensate for the increase in the thermal conductivity coefficient, in the form of a higher accumulation capability of the material and the retention of heat in the walls at a slight decrease in exterior temperature [36]. However, panel cores containing husks achieved, still, a much lower volumetric heat capacity than another agriculture by-product—corn husks [37].

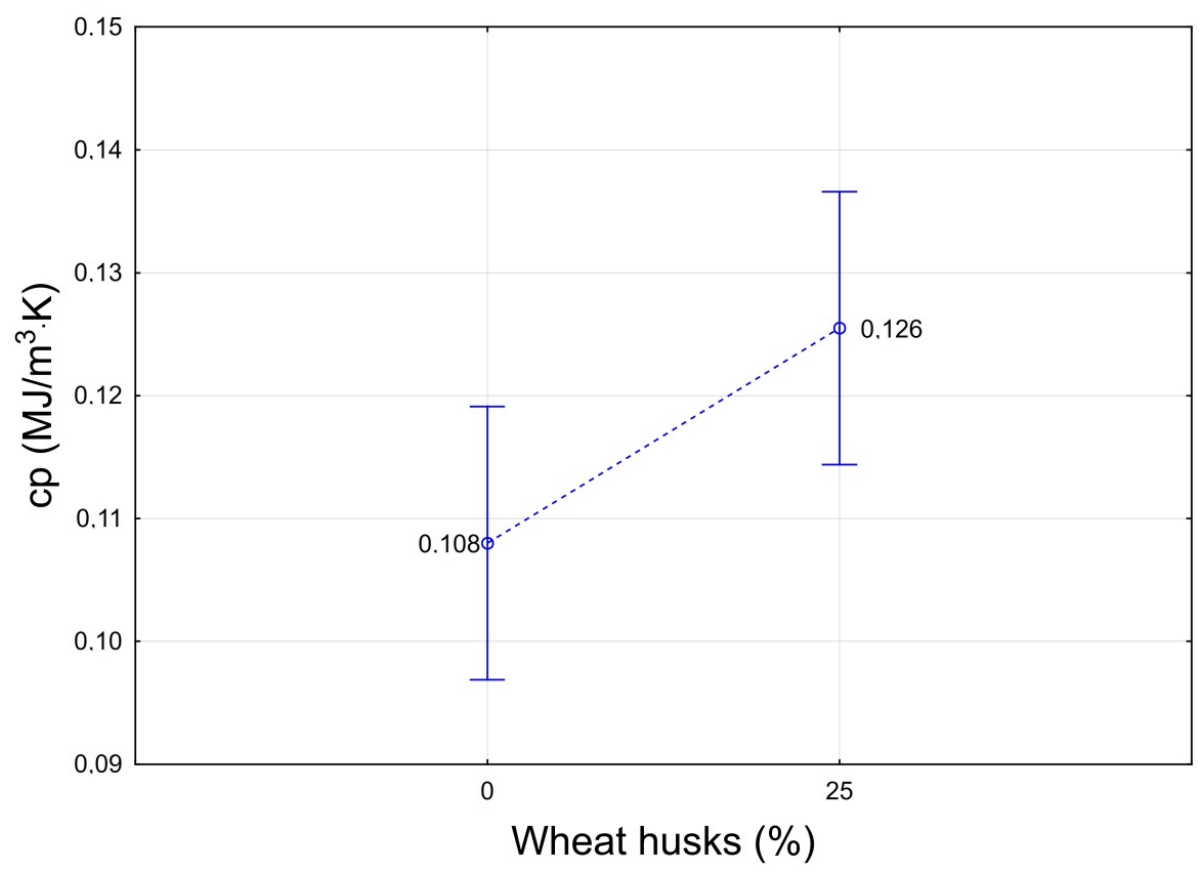

Figure 6. Influence of the proportion of the husk in the insulation board on volumetric heat capacity (cp).

Table 3 shows the calculated thermal conductivity coefficient values of the entire sandwich composite panels and the measured density values of the individual materials. There were slight deviations in the actual thermal insulation board densities from their nominal values. The influence of nanofiber membranes on thermal insulation properties or fire resistance was not evaluated. The geopolymer layer only slightly worsened the thermal insulation properties of the sandwich composite. The total thermal conductivity coefficient is around $0.05 \mathrm{~W} /(\mathrm{m} \cdot \mathrm{K})$, which is a fully adequate value for thermal insulation materials [9], and produced panels are comparable to other commonly used materials [38]. The reached thermal conductivity coefficients are higher than the thermal conductivity coefficients of commercially-produced heat insulation panels from PUR or PIR (polyisocyanurate) panels; however, the developed panels are from recycled materials and from recycled PUR that was initially not produced for thermal insulation.

Table 3. Average densities of materials and thermal conductivity of sandwich panels.

\begin{tabular}{|c|c|c|c|}
\hline $\begin{array}{c}\text { Recycled PUR:Wheat } \\
\text { Husk Ratio }\end{array}$ & $\begin{array}{l}\text { Heat Insulation Board } \\
\text { Density }\left(\mathrm{kg} / \mathrm{m}^{3}\right)\end{array}$ & $\begin{array}{c}\text { Geopolymer Density } \\
\left(\mathrm{kg} / \mathrm{m}^{3}\right)\end{array}$ & $\begin{array}{c}\lambda 20 / 65 \\
(\mathrm{~W} /(\mathrm{m} \cdot \mathrm{K}))\end{array}$ \\
\hline $1: 0$ & $49.4(1.7)$ & $885(32)$ & $0.049(0.006)$ \\
\hline $3: 1$ & $51.6(4.2)$ & $885(32)$ & $0.051(0.006)$ \\
\hline
\end{tabular}


There was a statistically significant effect of the proportion of husk in the thermal insulation core on its internal bonding (Figure 7). With an increase in the proportion of husk in the material, internal bonding was reduced to $0.64 \mathrm{kPa}$, which is already insufficient for thermal insulation materials according to standard EN 13162+A1 [39]. For the production of industrially-useable thermal insulation panels with winter wheat husk admixtures, it would then be necessary either to select a higher proportion of adhesive [40] or to include pre-treatment of wheat husks in the production process, in order increase their surface energy and thus reach higher bonding [5].

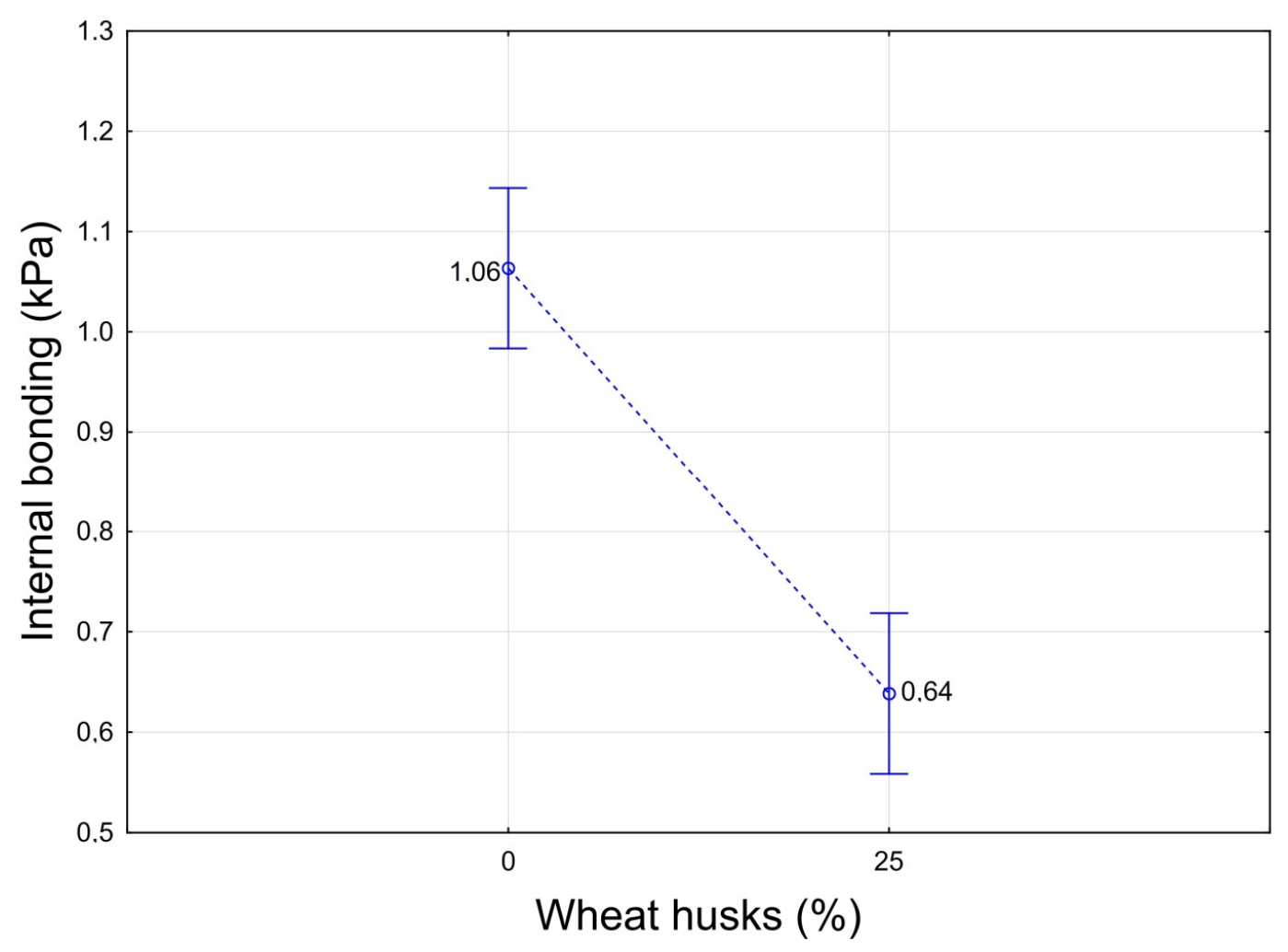

Figure 7. Influence of the proportion of the husk in the insulation board on internal bonding of composite materials.

The graphs in Figure 8 show the behavior of the entire panel under fire load. The samples were exposed to a flame with rapid (Figure 8a) and gradual (Figure 8b) temperature increases. No effect of the wheat husk additive on fire resistance was observed. However, the fire resistance of the boards was affected by the rate of temperature increase. In the case of a fast onset, the boards withstood the effect of flame for approximately $500 \mathrm{~s}$, and more than $800 \mathrm{~s}$ in the case of gradual onset. Regardless of the steepness of the onset temperature curve, it was observed that when the temperature inside the furnace rises to around $400{ }^{\circ} \mathrm{C}$, the temperature on the outer surface of thermal insulation boards increases to around $60{ }^{\circ} \mathrm{C}$, which is then held constant until the material burns. These results correspond with results for sandwich-structured composites made from rapeseed stalks [13], and, because of the flammable insulation core, the panel withstood lower temperatures than in [16], where geopolymer composites were filled only by basalt microfibrils. 

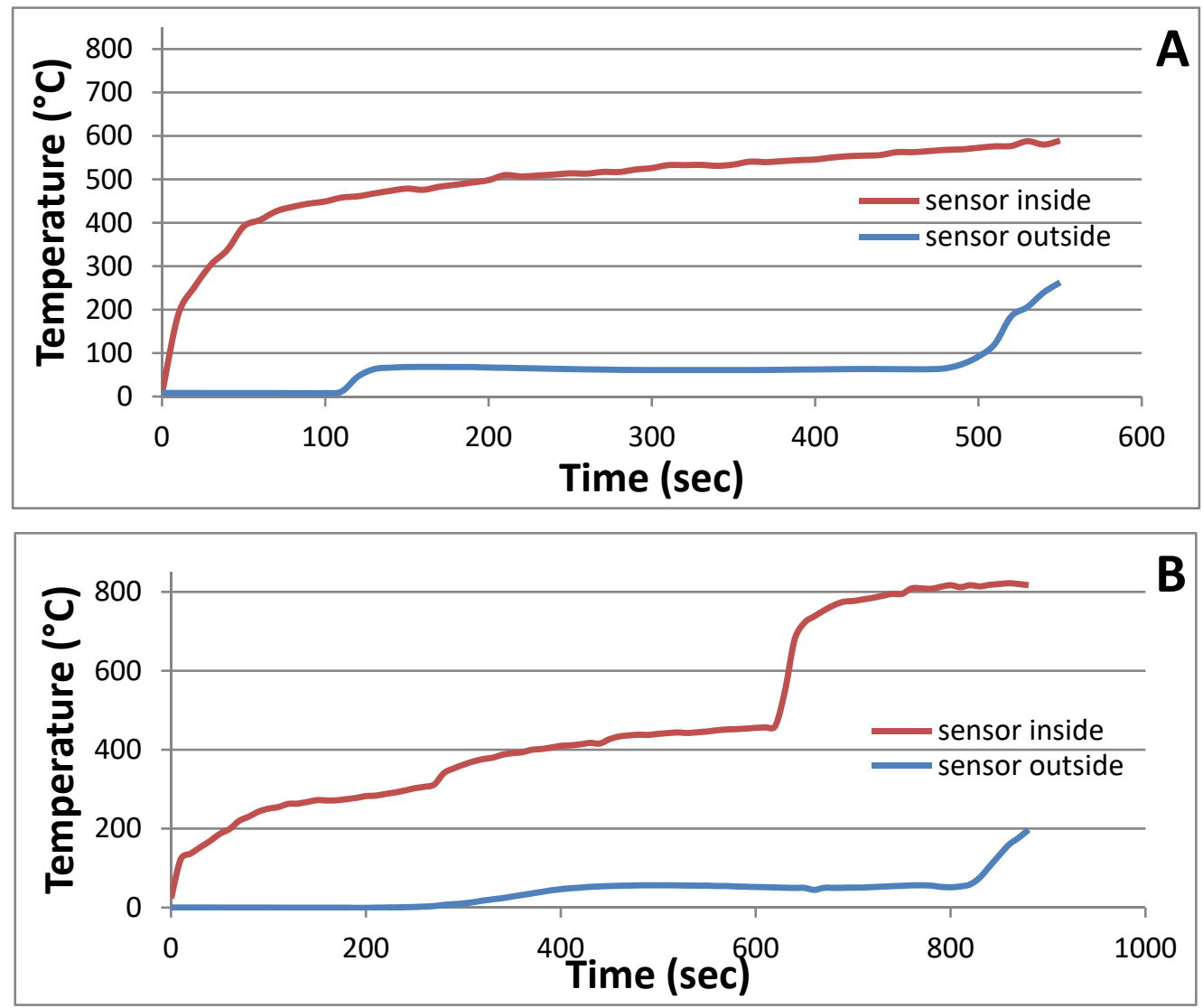

Figure 8. Burning characteristics of produced panels: (A) Rapid temperature increase; (B) gradual temperature increase.

The developed sandwich panels were able to withstand fairly long-term exposure to a water column with a height of $80 \mathrm{~cm}$. In $24 \mathrm{~h}$, only $486 \mathrm{~g}$ of water flowed through the $154 \mathrm{~cm}^{2}$ area (Figure 9). There was no difference found between the sandwich panel with the addition of husk and no husk. All of the resistance of the sandwich composite to the long-term effect of the water column is due to the used nanofibrous membrane and the interface between the nanofibrous membrane and the geopolymer. With regard to the thermal insulation sandwich panel without a nanofibrous membrane, this sandwich is virtually unable to prevent water flow. When the sandwich without a nanofibrous membrane was encumbered with a water column with a height of $80 \mathrm{~cm}, 3700 \mathrm{~g}$ of water flowed through the $154 \mathrm{~cm}^{2}$ area over $4 \mathrm{~min}$.

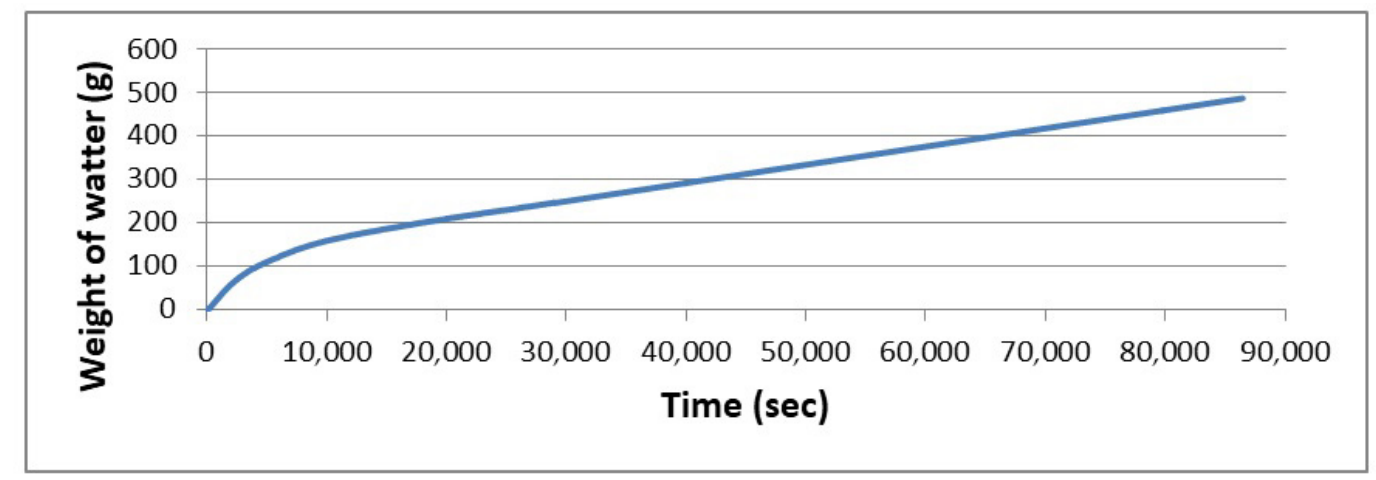

Figure 9. Effect of the nanofibrous membrane on the resistance of the sandwich panel against the long-term effects of the water column. 
The results show that the geopolymer layer in the entire sandwich panel suitably complements the thermal insulation core. The geopolymer layer provided the material with fire resistance, and it can be assumed that it would increase flexural strength [41], while only slightly worsening the overall thermal conductivity coefficient. The geopolymer layer was thoroughly bonded to the thermal insulation core, and in the tensile strength test perpendicular to the plane of the board, there was no breach between these layers, but in the insulation core. The nanofibrous membrane also contributed to improving the properties of the entire sandwich composite. It gave the material resistance to long-term exposure to the water column, while not negatively affecting any other material properties.

\section{Conclusions}

The paper presented properties of a sandwich panel from recycled materials enhanced by a geopolymer layer and a nanofibrous membrane. It was shown that the addition of husk to the thermal insulation core increased the thermal conductivity coefficient up to the value of $0.0452 \mathrm{~W} /(\mathrm{m} \cdot \mathrm{K})$, but this negative increase can be compensated by the increase in specific heat capacity of the insulation core with husks up to the value of $0.126 \mathrm{MJ} /\left(\mathrm{m}^{3} \cdot \mathrm{K}\right)$. The theoretical value of the thermal conductivity coefficient of the developed panels achieves excellent values on the level of $0.05 \mathrm{~W} /(\mathrm{m} \cdot \mathrm{K})$. The geopolymer layer and nanofibrous membrane provided the sandwich panel with the necessary properties for use as thermal insulation in exposed building walls, and fire resistance and water resistance increased nominally. The panel resisted fire with a gradual temperature increase for more than $13 \mathrm{~min}$, and incorporation of a nanofibrous membrane provided enhanced resistance to a water column with a height of $0.8 \mathrm{~m}$.

Author Contributions: Formal analysis, M.F.; investigation, Š.H., M.F., M.H., R.K., S.L.V. and H.L.C.; methodology, Š.H., M.H., L.F. and R.K.; project administration, P.L.; resources, P.L.; software, L.F. and H.L.C.; supervision, P.L.; writing—original draft, Š.H.; writing—review and editing, M.F., L.F., P.L. and S.L.V.

Funding: This research was funded by the Ministry of the Interior of the Czech Republic, grant number VI20172019055. The APC was funded by the Technical University of Liberec.

Acknowledgments: The results of the project "Application of Geopolymer Composites as Fire Barrier, AGK", registration number VI20172019055, were obtained through the financial support of the Ministry of the Interior in the program "The Safety Research of the Czech Republic" 2015-2020 (BV III/1-VS). This research was financed in part through a grand provided by the Technical University of Liberec-project SGS no. 21250.

Conflicts of Interest: The authors attest that there were no conflicts of interest with respect to this paper.

\section{References}

1. Asdrubali, F.; D'Alessandro, F.; Schiavoni, S.; Mencarelli, N. Sound absorption properties of reed. In Proceedings of the 22nd International Congress on Sound and Vibration, Florence, Italy, 12-16 July 2015.

2. Yarbrough, D.W.; Wikes, K.E.; Olivier, P.A.; Graves, R.S.; Vohra, A. Apparent thermal conductivity data and related information for rice hulls and crushed pecan shells. Therm. Cond. 2005, 27, 222-230.

3. Binici, H.; Eken, M.; Dolaz, M.; Aksogan, O.; Kara, M. An environmentally friendly thermal insulation material from sunflower stalk, textile waste and stubble fibres. Constr. Build. Mater. 2014, 51, 24-33. [CrossRef]

4. Goodhew, S.; Griffiths, R. Sustainable earth walls to meet the building regulations. Energy Build 2005, 37, 451-459. [CrossRef]

5. Hýsek, Š.; Podlena, M.; Bartsch, H.; Wenderdel, C.; Böhm, M. Effect of wheat husk surface pre-treatment on the properties of husk-based composite materials. Ind. Crops Prod. 2018, 125, 105-113. [CrossRef]

6. Kozłowski, R.; Mieleniak, B.; Muzyczek, M.; Mankowski, J. Development of insulation composite based on FR bast fibers and wool. In International Conference on Flax and Other Bast Plants; Saskatchewan Flax Development Commission: Saskatoon, SK, Canada, 2008; ID number: 68; pp. 353-363.

7. Battegazzore, D.; Alongi, J.; Duraccio, D.; Frache, A. Reuse and valorisation of hemp fibres and rice husk particles for fire resistant fibreboards and particleboards. J. Polymers Env. 2018, 26, 3731-3744. [CrossRef] 
8. Kain, G.; Lienbacher, B.; Barbu, M.C.; Senck, S.; Petutschnigg, A. Water vapour diffusion resistance of larch (Larix decidua) bark insulation panels and application considerations based on numeric modeling. Constr. Build. Mater. 2018, 164, 308-316. [CrossRef]

9. Asdrubali, F.; D'Alessandro, F.; Schiavoni, S. A review of unconventional sustainable building insulation materials. Sustain. Mater. Technol. 2015, 4,1-17. [CrossRef]

10. Intini, F.; Kühtz, S. Recycling in buildings: an LCA case study of a thermal insulation panel made of polyester fiber, recycled from post-consumer PET bottles. Int. J. Life Cycle Assess. 2011, 16, 306-315. [CrossRef]

11. Briga-Sá, A.; Nascimento, D.; Teixeira, N.; Pinto, J.; Caldeira, F.; Varum, H.; Paiva, A. Textile waste as an alternative thermal insulation building material solution. Constr. Build. Mater. 2013, 38, 155-160. [CrossRef]

12. Das, D.; Pradhan, A.K.; Chattopadhyay, R.; Singh, S.N. Composite nonwovens. Text. Prog. 2012, 44, 1-84. [CrossRef]

13. Hýsek, Š.; Frydrych, M.; Herclík, M.; Louda, P.; Fridrichová, L.; Le Van, S.; Le Chi, H. Fire-resistant sandwich-structured composite material based on alternative materials and its physical and mechanical properties. Materials 2019, 12, 1432. [CrossRef] [PubMed]

14. Dufkova, I.; Kovacic, V.; Louda, P. The effect of adding micro and inorganic nanoparticles on properties of geosilicate cured at temperature. In Proceedings of the 9th International Conference on Nanomaterials-Research and Application (Nanocon), Brno, Czech, 18-20 October 2017.

15. Toniolo, N.; Boccaccini, A.R. Fly ash-based geopolymers containing added silicate waste. A review. Ceramics Int. 2017, 43, 14545-14551. [CrossRef]

16. Behera, P.; Baheti, V.; Militky, J.; Louda, P. Elevated temperature properties of basalt microfibril filled geopolymer composites. Constr. Build. Mater. 2018, 163, 850-860. [CrossRef]

17. Rovnaník, P.; Al, S.O. Effect of curing temperature on the development of hard structure of metakaolin-based geopolymer. Constr. Build. Mater. 2010, 24, 1176-1183. [CrossRef]

18. Degirmenci, F.N. Freeze-thaw and fire resistance of geopolymer mortar based on natural and waste pozzolans. Ceram. Silik. 2017, 62, 1-9. [CrossRef]

19. Bakharev, T. Resistance of geopolymer materials to acid attack. Cem. Concr. Res. 2005, 35, 658-670. [CrossRef]

20. Villaquirán-Caicedo, M.A.; de Gutiérrez, R.M.; Sulekar, S.; Davis, C.; Nino, J.C. Thermal properties of novel binary geopolymers based on metakaolin and alternative silica sources. Appl. Clay Sci. 2015, 118, $276-282$. [CrossRef]

21. Hung, T.D.; Pernica, D.; Kroisova, D.; Bortnovsky, O.; Louda, P.; Rylichova, V. Composites Base on Geopolymer Matrices: Preliminary Fabrication, Mechanical Properties and Future Applications. Adv. Mater. Res. 2018, 55-57, 477-480. [CrossRef]

22. Le Chi, H.; Louda, P.; Periyasamy, A.P.; Bakalova, T.; Kovacic, V. Flexural behavior of carbon textile-reinforced geopolymer composite thin plate. Fibers 2018, 6, 87. [CrossRef]

23. Bastien, D.; Winther-Gaasvig, M. Influence of driving rain and vapour diffusion on the hygrothermal performance of a hygroscopic and permeable building envelope. Energy 2018, 164, 288-297. [CrossRef]

24. Arundel, A.V.; Sterling, E.M.; Biggin, J.H.; Sterling, T.D. Indirect health effects of relative humidity in indol environments. Environ. Health Perspect. 1986, 65, 351-361 101289/ehp8665351.

25. Simonson, C.J.; Salaonvaara, M.; Ojanen, T. Heat and mass transfer between indoor air and a permeable and hygroscopic building envelope: Part I - field measurements. J. Build. Phys. 2004, 28, 63-101 101177/1097196304044395. [CrossRef]

26. Simonson, C.J.; Salaonvaara, M.; Ojanen, T. Heat and mass transfer between indoor air and a permeable and hygroscopic building envelope: Part II - verification and numerical studies. J. Build. Phys. 2004, 28, 161-185. [CrossRef]

27. Fridrichová, L.; Frydrych, M.; Herclík, M.; Knížek, R.; Mayerová, K. Nanofibrous membrane as a moisture barrier. In Proceedings of the AIP Conference, Milano, Italy, 3-7 August 2018.

28. EN 323:1993 - Wood-Based Panels. Determination of Density; Eur. Comm. for Stand.: Brussels, Belgium, 1993.

29. EN 319:1993 - Particleboards and Fibreboards. Determination of Tensile Strength Perpendicular to the Plane of the Board; Eur. Comm. for Stand.: Brussels, Belgium, 1993.

30. Neuberger, P.; Kic, P. The use of unsteady method for determination of thermal conductivity of porous construction materials in real conditions. Agronomy Res. 2017, 15, 1119-1126.

31. EN 1363-2:1999_Fire Resistance Tests. Alternative and Additional Procedures; Eur. Comm. for Stand.: Brussels, Belgium, 1999. 
32. Ferrández-García, C.-E.; Ferrández-García, A.; Ferrández-Villena, M.; Hidalgo-Cordero, J.F.; García-Ortuño, T.; Ferrández-García, M.-T. Physical and mechanical properties of particleboard made from palm tree prunings. Forests 2018, 9, 755. [CrossRef]

33. Yuan, L.; Batra, R.C. Optimum first failure load design of one/two-core sandwich plates under blast loads, and their ultimate loads. Compos. Struct. 2019, 224. [CrossRef]

34. Panyakaew, S.; Fotios, S. New thermal insulation boards made from coconut husk and bagasse. Energy Build. 2011, 43, 1732-1739. [CrossRef]

35. Zhou, X.; Zheng, F.; Li, H.; Lu, C. An environment-friendly thermal insulation material from cotton stalk fibers. Energy Build. 2010, 42, 1070-1074. [CrossRef]

36. Pavelek, M.; Prajer, M.; Trgala, K. Static and dynamic thermal characterization of timber frame/wheat (Triticum Aestivum) chaff thermal insulation panel for sustainable building construction. Sustainability 2018, 10, 2363. [CrossRef]

37. Czajkowski, L.; Wojcieszak, D.; Olek, W.; Prybyl, J. Thermal properties of fractions of corn stover. Construct. Building Mater. 2019, 210, 709-712. [CrossRef]

38. Asdrubali, F.; Pisello, A.L.; D`Alessandro, F.; Bianchi, F.; Fabiani, C.; Cornicchia, M.; Rotili, A. Experimental and numerical characterization of innovative cardboard-based panels: Thermal and acoustic performance analysis and life cycle assessment. Building Env. 2016, 95, 145-159. [CrossRef]

39. EN 13162:2012+A1:2015-Thermal Insulation Products for Buildings. Factory Made Mineral Wool (MW) Products. Specification; Eur. Comm. for Stand.: Brussels, Belgium, 2015.

40. Tayeb, A.H.; Amini, E.; Ghasemi, S.; Tajvidi, M. Cellulose nanomaterials-binding properties and applications: A review. Molecules 2018, 23, 2684. [CrossRef] [PubMed]

41. Taveri, G.; Bernardo, E.; Dlouhy, I. Mechanical performance of glass-based geopolymer matrix composites reinforced with cellulose fibers. Materials 2018, 11, 2395. [CrossRef] [PubMed]

Sample Availability: All samples are available from the authors.

(C) 2019 by the authors. Licensee MDPI, Basel, Switzerland. This article is an open access article distributed under the terms and conditions of the Creative Commons Attribution (CC BY) license (http://creativecommons.org/licenses/by/4.0/). 